\title{
Current State of Internet Growth and Usage in Saudi Arabia and Its Ability to Support E- Commerce Development
}

\author{
Haya Alshehri \\ University of Salford / School of Computing, Science and Engineering \\ Salford, M5 4WT, UK \\ Email: h.alshehri1@edu.salford.ac.uk \\ Farid Meziane \\ University of Salford / School of Computing, Science and Engineering \\ Salford, M5 4WT, UK \\ Email: f.meziane@salford.ac.uk
}

\begin{abstract}
It is widely recognized that the Internet has been rapidly growing and massively used in recent years. Previous studies have revealed that this is true for Internet users across the world. Likewise it is reported, lack of ICT infrastructures and is one of the main reason behind lack of spread of E-Commerce. The study attempted to understand the state of Internet growth and activities usage and its ability to support E-Commerce development .Little attention has been paid to testing particular questions in this study which proper investigation can help in understanding the prospects of the development and adoption of E-Commerce. The current study will attempt to confirm on whether similar growth and usage of the Internet is also happening in Saudi Arabia and whether this will help in establishing a platform of E-Commerce development. Quantitative data was gathered from 606 Saudis living in various parts of Saudi Arabia. Four questions related to the use of the Internet in Saudi Arabia are tested. The outcome shows that the findings are similar to those of other countries. In addition, individuals' readiness to use the Internet as their main shopping medium is approved by more than half of the sample used.
\end{abstract}

Keywords: Internet Usage, E-Commerce, Saudi Arabia, Quantitative Research.

\section{INTODUCTION}

The Internet is one of the most significant innovations that influenced lifestyles. Business, education, healthcare, and environment have all gained from the development of the Internet when they changed to online usage and transactions.

1

${ }^{1}$ Haya Alshehri
The fast progress of the Internet has offered a novel host of chances in addition to threats [1]. To take advantage of the benefits of using the Internet, it is important that individuals, governments and companies understand the threats and benefits of going online. Trust in these new technologies will be paramount to their acceptance, adoption and success. In addition to trust, developing countries face more technical challenges such as the cost of telephone tariff and Internet, technical support and hardware [2]. The Arab work is facing similar challenges that slow the development of the Internet and related applications [3]. It has been noted that the increasing access to Internet demonstrates the country's readiness for ECommerce, and indeed this will require the support of the governments and businesses [4]. It was tested that the development of Internet environments influences Saudi customers to engage in E-Commerce and buy online [5]. Therefore, the purpose of this study is to examine the current state of Internet relative growth and usage in Saudi Arabia as the foundation of a research to develop a framework for the adoption and development of ECommerce; The Internet being the backbone for the implementation of B2C E-Commerce.

Although, the results reported in this paper are based on a questionnaire survey of 606 Saudi citizens living across Saudi Arabia, the main issues that were tested are the following four questions:

- 'Where do you access the Internet?'

- 'Which medium do you use to access the Internet?'

- How often do you access the Internet?'

- 'When you access the Internet, how many hours a week do you use it for?' 
- 'Are you ready to use the Internet as your main shopping medium?'

The remaining paper is organized as follows. In section 2 we provide a background review for this study in the form of a literature review, in section 3 the research methodology is described. The finding and analysis of the study are presented in section 4 . Finally the study conclusions are given in section 5 .

\section{LITERRATURE REVIEW}

\section{A. Background}

Prior to the late 90s, access to the Internet in Saudi Arabia was limited [6]. Furthermore, according to TIAC [7], the technical difficulties associated with the use of Arabic on the Internet (and on computers more generally), tended to restrict Internet use to only those who could work in English. Using Communication and Internet Technologies (ICT), the total number of Internet users had increased to 6.4 million, representing about $26 \%$ of Saudi citizens by the end of 2008, compared with only 200,000 in 2000 [8]. However, Saudi Arabia has the highest percentage of mobile phone users in the world, with $95 \%$ of individuals having a mobile phone. As a result, mobile Internet penetration has grown to $54 \%$ with $70 \%$ mobile Internet usage rates [9]. In 2014, the total IT expenses are predicted to reach US\$ 5.7 billion; with each person's expenses reaching US\$200. These figures represent a $13 \%$ rise in two years, and account for over $50 \%$ of overall ICT investments throughout the Gulf Co-operation Council (GCC) countries [9].

However, currently Saudi Arabia, like the rest of the Middle East, and indeed the Arab World, has very little global market share of the income generated by E-Commerce. In this respect, it is the USA and Europe which are the biggest beneficiaries, sharing around $79 \%$ of the income generated worldwide, while the smallest share representing about 3\% is occupied by Africa and the Middle East [10]. Worries about security, cultural and political focuses are the key issues that slow down the implementation of Internet transactions in the Arab World [3, 11].

\section{$B$. Internet and E-Commerce}

The Internet is one of the significant actors in the implementation of many new innovations such as E- Business, E-Commerce, E-Marketing and MCommerce. It is the main way of offering online services. Businesses that seek to use the Internet in the marketplace in the developing world might be facing vital difficulties, more than those in the developed countries. One of the significant effects of the Internet on business is E-Commerce [12]. ECommerce is seen as a revolution in the business world as it added new features to the whole process of trade guarantying smart, more rapid services in related segments of information [13]. E-Commerce offers services that enable customers to purchase, sell, and pay via the World Wide Web (WWW). Customers are allowed to buy from markets around the world without seeing the goods or trying the services. To implement E-Commerce, it is important that companies adopt the new technologies like the Internet. Lack of telecommunication infrastructures is often cited as the main reason behind the limitation of the Internet in developing countries [2]. One of the key threats that face the spread of E-Commerce is the lack of Internet access [2]. This is true in the Arab world [3]. E-Commerce requires an appropriate and a full development plan to fulfil its potential and the availability of an adequate ICT infrastructure is essential for the implementation of such a plan [14]. A large number of Arab countries need to fully embrace and develop the Internet to get its full benefits and advantages [3]. The situation is similar in many developing countries where ICT infrastructures are not well developed, hence slowing the development of E-Commerce [15].

B2C E-Commerce deals with customers buying goods from businesses. It has been known that B2C in developed countries has a high level of growth [15]. Different changes of shopper's behaviour by ICT infrastructure growth, it was found that the main influences of the development of ECommerce are the rising value of 'Internet users, online spending and adoption of new technologies' [14]. These results can be similar to implement ECommerce in developing countries like Saudi Arabia.

There is currently a wide gap in the use and development of the Internet between the Arab World and the developed world and the gap is widening. Large numbers of businesses are quite hesitant in adopting online shopping because of the high cost of Internet use. It is hard for countries in the Arab world to achieve the same levels of Internet development in general and E-Commerce in particular as that of the developed countries. ECommerce can be implemented in this rapid and wider digital economic growth and investigates the E-Commerce implementation in different countries, especially in developing countries to increase the awareness of B2C EC in Saudi Arabia.In Saudi Arabia the E-Commerce infrastructure is not forthcoming because of the monopoly of Internet service providers [15]. However, people in Saudi Arabia can drive forward the use of E-Commerce but the correct infrastructure is required [15]. In respect of the large proportion of young people in Saudi Arabia's population, it can be seen that they use mobile and Internet communication more as social media tools [9]. Hence, there is already a record of implementation and use of Business-toCustomer (B2C) E-Commerce within Saudi Arabia, 
it is being shown that about $39 \%$ of adult Internet users purchase goods and makes payments for services online via E-Commerce facilities [16]. Table 1 shows the Internet growth and population in Saudi Arabia [17].

TABLE 1: INTERNET GROWTH AND POPULATION STATISTICS' IN SAUDI

ARABIA

\begin{tabular}{|c|c|c|c|c|c|}
\hline \multirow[b]{2}{*}{$\mathrm{N}$} & \multicolumn{5}{|c|}{ Internet in Saudi Arabia } \\
\hline & Year & Users & Population & $\%$ & $\begin{array}{c}\text { Usag } \\
\mathrm{e} \\
\text { Sour } \\
\text { ce }\end{array}$ \\
\hline 1 & 2000 & 200,000 & $21,624,422$ & $0.9 \%$ & ITU \\
\hline 2 & 2003 & $\begin{array}{l}1,500,00 \\
0\end{array}$ & $21,771,609$ & $6.9 \%$ & ITU \\
\hline 3 & 2005 & $\begin{array}{l}2,540,00 \\
0\end{array}$ & $23,595,634$ & $10.8 \%$ & $\begin{array}{l}\mathrm{C}+\mathrm{I}+ \\
\mathrm{A}\end{array}$ \\
\hline 4 & 2007 & $\begin{array}{l}4,700,00 \\
0\end{array}$ & $24,069,943$ & $19.5 \%$ & $\underline{\text { ITU }}$ \\
\hline 6 & 2009 & $\begin{array}{l}7,761,80 \\
0\end{array}$ & $28,686,633$ & $27.1 \%$ & $\underline{\text { ITU }}$ \\
\hline 7 & 2010 & $\begin{array}{l}9,800,00 \\
0\end{array}$ & $25,731,776$ & $38.1 \%$ & $\underline{\text { ITU }}$ \\
\hline 8 & 2012 & $\begin{array}{l}13,000,0 \\
00\end{array}$ & $26,534,504$ & $49.0 \%$ & IWS \\
\hline
\end{tabular}

\section{RESEARCH METHODOLOGY}

This study conducted a survey method to examine Saudis attitudes towards the Internet usage activities in Saudi Arabia. This method is one of the methods that give primary data. It is information that is collected directly by the researcher through working in the field. What is important about primary data is that it can throw new light on a topic and add to existing published knowledge, or even help to create a new stream of literature. This method enabled to achieve an experiential investigation of phenomenon in its real life environment of a big young population where they have the ability to use the Internet. In this section of the research, a pilot study was conducted by questionnaires and it was validated. The questionnaire was designed in English and then translated into the Arabic Language. The data was collected over a period of 12 weeks in Saudi Arabia, A drop and collect technique was used. Descriptive analysis of frequency and percentages were performed via the SPSS software. The results reported in this paper are part of a larger study which is trying to improve the understanding of the advantages of the Internet in Saudi Arabia for the development of a framework for the development of E-Commerce.

\section{FINDINGS AND ANALYSIS}

\section{A. Sample Demographic Information}

Saudi citizens' gender information is given in Table 2. Out of the 606 respondents, 213 are males; representing $(35.1 \%)$ of the sample and 393 females $(64.9 \%)$.

TABLE2: GENDER DISTRIBUTON

\begin{tabular}{|c|l|l|l|}
\hline \multirow{2}{*}{$\mathrm{N}$} & \multicolumn{3}{|c|}{ Gender } \\
\cline { 2 - 5 } & Items & Frequency & Percent \\
\hline 1 & Males & 213 & 35.1 \\
\hline 2 & Females & 393 & 64.9 \\
\hline 3 & Total & 606 & 100.0 \\
\hline
\end{tabular}

Table 3 shows the age distribution of the sample. The age group from 25-34 years old was the largest with 244 respondents $(40.3 \%)$. The second largest group is the $18-24$ group $(29.70 \%)$ and the third is the 35-44 group (24.42\%), the age group greater than 55 years old was the smallest, containing only two respondents $(3 \%)$.

TABLE 3: AGE DSTRIBUTION

\begin{tabular}{|c|l|l|}
\hline \multirow{2}{*}{$\mathrm{N}$} & \multicolumn{3}{|c|}{ Age } \\
\cline { 2 - 4 } & Items & Percent \\
\hline 1 & $18-24$ & 29.70 \\
\hline 2 & 25.34 & 40.3 \\
\hline 3 & $35-44$ & 24.42 \\
\hline 4 & $45-54$ & 5.28 \\
\hline 5 & $>55$ & .33 \\
\hline 6 & Total & 100.0 \\
\hline
\end{tabular}

Table 4 summarizes the level of instruction of the participants. The nearly half of the respondents are educated, it can be observed that people holding a Bachelor degree were the highest with a frequency of $301(49.7 \%)$. Second level is under diploma $(22.11 \%)$, third level is diploma $(16.01 \%)$, the higher level of education is $(10.23 \%)$ and the smallest is other (1.98\%).

TABLE 4: LEVEL OF INSTRUCTION OF PARTICIPANTS

\begin{tabular}{|c|l|c|}
\hline \multirow{2}{*}{$\mathrm{N}$} & \multicolumn{2}{|c|}{ Instruction } \\
\cline { 2 - 3 } & Items & \multicolumn{1}{|c|}{ Percent } \\
\hline \multirow{2}{*}{1} & Under Diploma & 22.11 \\
\hline
\end{tabular}




\begin{tabular}{|c|l|l|}
\hline \multirow{2}{*}{$\mathrm{N}$} & \multicolumn{2}{|c|}{ Instruction } \\
\cline { 2 - 4 } & Items & 16.01 \\
\hline 2 & Diploma & 49.67 \\
\hline 3 & Bachelor & 10.23 \\
\hline 4 & Master and $\mathrm{PhD}$ & 1.98 \\
\hline 6 & Other & 100 \\
\hline 7 & Total & \\
\hline
\end{tabular}

Table 5 summarizes the occupation distribution of the participants. The largest group is employed $(60.23 \%)$. The second is students $(26.57 \%)$, and the other rest around between 4 and $5 \%$.

TABLE 5: OCCUPATION

\begin{tabular}{|c|l|l|}
\hline \multirow{2}{*}{$\mathrm{N}$} & \multicolumn{2}{|c|}{ Occupation } \\
\cline { 2 - 4 } & Items & Percent \\
\hline 1 & Students & 26.57 \\
\hline 2 & Employee & 60.23 \\
\hline 3 & Retired & 2.81 \\
\hline 4 & Housewife and Husband & 4.29 \\
\hline 6 & Other & 4.95 \\
\hline 7 & Total & 100 \\
\hline
\end{tabular}

Table 6 shows the respondents came from all over the five regions in Saudi Arabia, but representation from the middle region was highest, reaching $46.4 \%$. This was followed by the north with $19.64 \%$ of the research population, then the south being represented by $13.2 \%$, the west with $12.21 \%$, and finally the east with only $8.91 \%$.

\section{TABLE 6: REGIONS DISTRIBUTION}

\begin{tabular}{|c|l|l|}
\hline \multirow{2}{*}{$\mathrm{N}$} & \multicolumn{2}{|c|}{ Region } \\
\cline { 2 - 4 } & Items & Percent \\
\hline 1 & Middle & 46.04 \\
\hline 2 & East & 8.91 \\
\hline 3 & West & 12.21 \\
\hline 4 & North & 19.64 \\
\hline 5 & South & 13.20 \\
\hline 6 & Total & 100.0 \\
\hline
\end{tabular}

Table 7 shows the responses to the question "When did you start using the Internet?" The results show that approximately one quarter $(24.9 \%)$ of the sample began to use the Internet between 1998 and 2001. However, the highest group (31.2\%) began to use the Internet immediately after that period, between 2002 and 2005, and this was followed by another group representing $29 \%$ of the sample that began Internet use between 2006 and 2009. A further $14.9 \%$ of the sample did not start using the Internet until 2010. These figures indicate that the Internet has been established in Saudi Arabia since 1998 and that its popularity grew relatively quickly.

TABLE 7: WHEN DID YOU START USING THE INTERNET?

\begin{tabular}{|c|l|l|l|}
\hline \multirow{2}{*}{$\mathrm{N}$} & \multicolumn{3}{|c|}{ Start date of using the Internet } \\
\cline { 2 - 5 } & Items & Frequency & Percent \\
\hline 1 & $1998-2001$ & 151 & 24.9 \\
\hline 2 & $2002-2005$ & 189 & 31.2 \\
\hline 3 & $2006-2009$ & 176 & 29.0 \\
\hline 4 & $2010-$ Now & 90 & 14.9 \\
\hline 5 & Total & 606 & 100.0 \\
\hline
\end{tabular}

Regarding the pattern of Internet usage, Table 8 shows that $61.9 \%$ of participants used the Internet at home, and $23.6 \%$ accessed it from home and work. Only $3.5 \%$ of respondents used the services of an Internet café. These percentages may well reveal that the population prefers to conduct personal online research through the use of homebased $\mathrm{Wi}-\mathrm{Fi}$, which offer them greater privacy.

TABLE 8: WHERE DO YOU ACCESS THE INTERNET?

\begin{tabular}{|c|l|l|l|}
\hline \multirow{2}{*}{$\mathrm{N}$} & \multicolumn{3}{|c|}{ Access the Internet } \\
\cline { 2 - 5 } & Items & Frequency & Percent \\
\hline 1 & Home & 375 & 61.9 \\
\hline 2 & Work & 21 & 3.5 \\
\hline 3 & Internet café & 8 & 1.3 \\
\hline 4 & Other & 17 & 2.8 \\
\hline 5 & Home and work & 143 & 23.6 \\
\hline 6 & Home and Internet café & 4 & .7 \\
\hline 7 & Home, work and Internet café & 30 & 5.0 \\
\hline 8 & $\begin{array}{l}\text { Home, work, Internet café and } \\
\text { other }\end{array}$ & 8 & 1.3 \\
\hline 9 & Total & 606 & 100.0 \\
\hline
\end{tabular}

The responses to Question 3 regarding the medium used to access the Internet, the results are summarised in Table 9. 29.9\% reported using all media (PC, tablet, and smart phone), and $24.8 \%$ indicated using only a PC, thus implying that the improvement of ICT in Saudi Arabia is enabling 
the younger population to access the Internet in different ways.

TABLE 9: WHICH MEDIUM DO YOU USE TO ACCESS THE INTERNET?

\begin{tabular}{|c|l|l|l|}
\hline \multirow{2}{*}{$\mathrm{N}$} & \multicolumn{3}{|c|}{ Medium use to access the Internet } \\
\cline { 2 - 5 } & Items & Frequency & Percent \\
\hline 1 & PC & 150 & 24.8 \\
\hline 2 & Tablet & 28 & 4.6 \\
\hline 3 & Smart phone & 93 & 15.3 \\
\hline 4 & All & 181 & 29.9 \\
\hline 5 & PC and smart phone & 118 & 19.5 \\
\hline 6 & Tablet and smart phone & 32 & 5.3 \\
\hline 7 & PC and Tablet & 4 & .7 \\
\hline 8 & Total & 606 & 100.0 \\
\hline
\end{tabular}

Table 10 shows that the majority of respondents $(68 \%)$ access the Internet more than once a day but it is not known what they do during this time (i.e. play games, communication, social media, work, online shopping). Only $4.1 \%$ indicated that they access the Internet as little as once or twice a month.

TABLE 10: HOW OFTEN DO YOU ACCESS THE INTERNET?

\begin{tabular}{|c|l|l|l|}
\hline \multirow{2}{*}{$\mathrm{N}$} & \multicolumn{3}{|c|}{ Often access the Internet } \\
\cline { 2 - 4 } & Items & Frequency & Percent \\
\hline 1 & Once or twice a month & 25 & 4.1 \\
\hline 2 & Three to four times a week & 78 & 12.9 \\
\hline 3 & Once everyday & 86 & 14.2 \\
\hline 4 & More than once a day & 417 & 68.8 \\
\hline 5 & Total & 606 & 100.0 \\
\hline
\end{tabular}

Table 11 shows that in terms of the amount of time spent using the Internet each week, the category which attracted the highest proportion of respondents was that of more than 1 hour and less than 55 hours (showing 37.3\%), whereas only $13.2 \%$ used the Internet for over 20 hours a week.

TABLE 11: HOW MANY HOURS A WEEK DO YOU USE THE INTERNET?

\begin{tabular}{|c|l|l|l|}
\hline \multirow{2}{*}{$\mathrm{N}$} & \multicolumn{3}{|c|}{ Hours of using the Internet per a week } \\
\cline { 2 - 5 } & Items & Frequency & Percent \\
\hline 1 & Less than 1 hour & 68 & 11.2 \\
\hline 2 & $\begin{array}{l}\text { More than 1 hour and less than 5 } \\
\text { hours }\end{array}$ & 226 & 37.3 \\
\hline 3 & $\begin{array}{l}\text { More than 5 hours and less than 10 } \\
\text { hours }\end{array}$ & 132 & 21.8 \\
\hline 4 & $\begin{array}{l}\text { More than 10 hours and less 20 } \\
\text { hours }\end{array}$ & 100 & 16.5 \\
\hline 5 & Over 20 hours & 80 & 13.2 \\
\hline
\end{tabular}

\begin{tabular}{|c|l|l|l|}
\hline \multirow{2}{*}{$\mathrm{N}$} & \multicolumn{3}{|c|}{ Hours of using the Internet per a week } \\
\cline { 2 - 4 } & Items & Frequency & Percent \\
\hline \multirow{2}{*}{6} & Total & 606 & 100.0 \\
\hline
\end{tabular}

In respect of their readiness to use the Internet as their main shopping medium, a small majority of respondents $(52.5 \%)$ believed that they were ready, whilst $47.5 \%$ considered that they were not. These responses are shown in Table 12.

TABLE 12: ARE YOU READY TO USE THE INTERNET AS YOUR MAIN SHOPPING MEDIUM?

\begin{tabular}{|c|l|l|l|}
\hline \multirow{2}{*}{$\mathrm{N}$} & \multicolumn{3}{|c|}{ Main shopping medium } \\
\cline { 2 - 5 } & Items & Frequency & Percent \\
\hline 1 & Yes & 318 & 52.5 \\
\hline 2 & No & 288 & 47.5 \\
\hline 3 & Total & 606 & 100.0 \\
\hline
\end{tabular}

\section{DISCUSSION}

The literature has outlined that Internet is the backbone of the development of E-Commerce. When populations engage in Internet usage, they have a better understanding of the issues and threats associated with it. A better education will make turn them into confident users that may then pave the way of E-Commerce adoption and engagement. This study has confirmed what other studies have shown in terms of Internet Usage growth in other countries to Saudi Arabia. There is a growth in Internet usage although this is slow and late compared to other countries. Indeed, the study has shown that $44 \%$ of the population has started using the Internet after 2006. A time when most people in the developed world are fully using the internet and E-Commerce well developed. This section of the population that started using the Internet late, may not be fully ready to engage in ECommerce and may still be hesitant at providing for examples their personal details or payments details. Nevertheless, it is very encouraging to see that although the sample covered large parts of Saudi Arabia, $100 \%$ of the sample participants are Internet users.

The usage of the Internet mainly at home also shows that Internet has penetrated most Saudi households. Given the nature of the Saudi society and families, shopping is a family and friends activity. When established, this could be a positive point in the adoption of E-Commerce. Another aspect that this study has shown is the use of various media by Saudis. This means that there is not only scope for the development of ECommerce but also for M-Commerce and the use of smart phones and tablets to engage in commercial and services transactions. There are already some studies that show that the Saudi population is already engaged in E-Commerce. A study commissioned by IMRG has shown that $39 \%$ 
of the Saudi Adult population is engaged in ECommerce and make online payments.

The study has also shown that there is a moderate usage of Internet by Saudis with over $50 \%$ of the population uses the Internet between one to ten hours. Nearly $70 \%$ of the population using the Internet more than once a day.

\section{CONCLUSION}

This research contributes to the knowledge of Internet activities usage in Saudi Arabia and to have a better understanding of the Saudi society behavior towards the Internet. Furthermore, to the direct question on whether the sample population is ready to use the Internet as their main shopping medium, over half of the population answered yes. However, as many studies have shown, acceptance by the populations alone may not be sufficient for the development of E-Commerce. Legislations and the support from the governments and financial institutions are also needed for the full implementation of E-Commerce.

The support of the government in Saudi Arabia [4] and the results obtained from this study confirms the readiness of Saudi Arabia to embrace E-Commerce. However, we agree that this study alone may not provide all the answers to the readiness of the Saudi society for the adoption of E-Commerce. Indeed, the work reported in this paper is only a part of a larger study conducted by the authors.

To confirm the early results of this study, the following investigations are also being conducted:

- Perception of the sample on the use and usefulness of E-Commerce looking at both the technological, cultural and societal variables.

- Similar study is also conducted for Saudis living abroad, in this case the UK [5]. This study investigate whether the environment influence the change in the habits and attitudes towards E-Commerce.

- A comparative study between the two samples is analyzed.

- Finally, a qualitative study about the perception of companies and organization of E-Commerce is conducted.

- The results of these studies is used to develop a framework for the development and implementation of E-Commerce in Saudi Arabia.

\section{REFERENCES}

[1] M. Tan and T. S. Teo, "Factors influencing the adoption of Internet banking," Journal of the Association for Information System, vol. 1 issue 1, Article 5. 2000.
[2] S. Hawk, "A comparison of B2C e-commerce in developing countries," Electronic Commerce Research, vol. 4, no. 3, 181-199, 2004.

[3] A.M. Aladwani, "Key Internet Characteristics and ECommerce Issues in Arab Countries," Information Technology \& People, vol. 16 no. 1, pp. 9-20, 2003.

[4] S. M. Sait, K. M. Al-Tawil, and S.A. Hussain, "E-commerce in Saudi Arabia: adoption and perspectives" AJIS, vol. 12, no. 1, pp. 54-74, 2004.

[5] H. Alshehri, and F. Meziane, "An Investigation into Saudi Online Shoppers' Behaviour Abroad," In Developments in eSystems Engineering (DeSE), Sixth International Conference, Abu Dhabi, 2013, pp. 323327. IEEE.

[6] Electronic Frontiers, (2002). Internet Censorship: Law and policy around the world. Australia. [Online] https://www.efa.org.au/Issues/Censor/cens3.html\#sau,

last accessed in 13-07-2014.

[7] TIAC (The Internet in the Arab Countries). (2009). Development and growth of the Internet. [Online] http://www.al-bab.com/media/internet.htm, last accessed in 14 July 2014.

[8] CITC (Communications and Information Technology Commission). (2007). Internet Usage Study in the Kingdom of Saudi Arabia Communication and Information Technology Commission, Riyadh.

[9] SOCG (Sacha Orloff Consulting Group). (2012). ECommerce in Saudi Arabia: Driving the evolution, adaption and growth of e-commerce in the retail industry,[online] http://sacha-orloff-group.com, last accessed in 12 March 2014.

[10] R. AlGhamdi, S. Drew, and W. Al-Ghaith, "Factors influencing EC adoption by retailers in Saudi Arabia: a qualitative analysis" The Electronic Journal on Information Systems in Developing Countries, vol. 47, no. 7, pp.1-23, 2011a.

[11] W. Alrawabdeh, D. Zeglat, and A. Alzawahreh, "The Importance of Trust and Security Issues in ECommerce Adoption in the Arab World," European Journal of Economics, Finance and Administrative Sciences, vol. 52, ISSN, 1450-2275, pp. 72-78, 2012.

[12] N. Kamalabadi, A. Bayat, P. Ahmadi and A. Ebrahimi, "Identifying and Prioritization of Challenges and Barriers of EC Implementation in Iran," World Applied Sciences Journal, vol. 5, no. 5, pp. 590-597, 2008.

[13] S. A. A. Rajon, Abdullah-Al-Nahid and A. S. M. Arif, "A Generic Framework for Implementing Electronic Commerce in Developing Countries," IJCIT, 2078-5828, vol. 01, no. 02, pp. 42-53, 2011.

[14] M. Jehangir, P.D.D. Dominic, Naseebullah, and A. Khan, "Towards Digital Economy: The Development of ICT and E-Commerce in Malaysia", Modern Applied Science, Vol. 5, No. 2. Pp. 171-178, 2011.

[15] R. AlGhamdi, S. Drew, O. AlFaraj, "Issues Influencing Saudi Customers' Decisions to Purchase from Online Retailers in the KSA: A Qualitative Analysis," European Journal of Scientific Research, vol.55, no 4, pp.580-593, $2011 \mathrm{~b}$.

[16] IMRG (International Commissioned by Visa Middle East). (2011). Gulf Cooperation Council B2C Overview. London,. [Online] http://www.imrg.org, last accessed in 12 May 2015.

[17] IWS (Internet World State). (2012). Internet usage, broadband and telecommunications reports. [online],http://www.Internetworldstats.com/me/sa.htm, last accessed 19 May 2015. 
Haya Alshehri is a $\mathrm{PhD}$ students in the school of computing, Science and Engineering at the university of Salford, UK. She was born in Saudi Arabia in 1974. She got king Abdullah scholarship program for studying a $\mathrm{PhD}$ in information system with specialism in E-Commerce and hold a MBA from King Abdulaziz University, Saudi Arabia. Her principal research interest lies in the field of ECommerce researching the impact of different environment on customer activities on ECommerce. She got award for scientific excellence of Saudi Arabia Cultural Bureau in Britain and Ireland four times for every academic year during her $\mathrm{PhD}$.

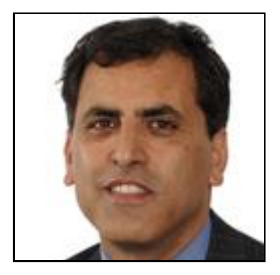

Farid Meziane (PhD) is a professor of computer science at the University of Salford, $\mathrm{UK}$ and holds a $\mathrm{PhD}$ in Computer Science from the same university. He is currently the director of the Informatics Research Centre at the University of Salford. His research interests include Data and knowledge Engineering, Natural Language Processing and ECommerce. He is serving in the research committee of over 20 conferences and is the co-chair of the international conference on application of Natural Language to Information Systems (NLDB). 